\title{
UNUSUAL PROPERTIES OF STAPHYLOCOCCUS AUREUS STRAINS OF THE NEW EPIDEMIC PHAGE TYPE 95
}

\author{
VIBEKE T. RosDahl aNd KiRSTEN ROSENDAL*
}

Institute of Medical Microbiology, University of Copenhagen, Juliane Mariesvej 22, DK-2100 Copenhagen and *Department of Hospital Infections, State Serum Institute, Amager Boulevard 80, DK-2300, Copenhagen, Denmark

\begin{abstract}
Summary. Three hundred and seventy-one penicillin-resistant Staphylococcus aureus strains of phage type 95 isolated in the years 1977-1983 were investigated. They had characteristic resistance patterns to cadmium $(\mathrm{Cd})$, arsenate (As) and mercury $(\mathrm{Hg})$. Most were susceptible to all three heavy metals; 25 strains were resistant to As only and one to Cd and As. The susceptible strains had a uniform medium level of penicillinase production, whereas the As-resistant strains produced large amounts of penicillinase. In most of the strains, penicillin resistance was located on a very unstable penicillinase plasmid.

The combinaton of rare properties found in Danish type-95 strains seems to point to the spread of one or two clones. Co-reactions with other phage groups or complexes and results of lysogenisation experiments suggest that the Danish type-95 strains are derived from strains of the $52,52 \mathrm{~A}, 80,81$ complex.
\end{abstract}

\section{INTRODUCTION}

When staphylococci of the 52, 52A, 80, 81 and $83 \mathrm{~A}$ phage-type complexes appeared, it was possible to designate probable ancestor(s) by demonstrating evolutionary processes that might have operated (Asheshov and Winkler, 1966; Jevons et al., 1966). The results of these investigations led to the assumption that strains of phage type 80/81 might belong to one clone (Asheshov and Winkler, 1966), whereas members of the 83A complexes might have different ancestors (Jevons et al., 1966).

In recent years, strains of phage type 95 have spread in Denmark. Among Staphylococcus aureus isolates from cases of bacteraemia, the occurrence increased from $1 \%$ in 1972 to $9 \%$ in 1981 (Rosendal et al., 1983), and among the 20000 strains phage-typed in Denmark in 1983,12\% were of phage type 95 . The present investigation considers the one-clone theory in relation to type-95 strains spreading in Denmark.

\section{MATERIALS AND METHODS}

Staphylococcus aureus strains. All the Danish S. aureus strains were isolated from cases of bacteraemia (Jessen et al., 1969; Rosendal et al., 1976; Rosendal et al., 1983). Among the strains of phage type $95,90 \%$ were resistant to penicillin, but only $4 \%$ were resistant to one or more other 
antibiotics including tetracycline, streptomycin, erythromycin, kanamycin and chloramphenicol.

In the present investigation, 287 penicillin-resistant type-95 strains isolated during the years 1977-1982 were investigated, together with nine type-95 strains isolated before 1977 and 84 strains isolated in 1983. Seven penicillin-resistant type-95 strains isolated in England in 1984 were received from Mrs M. de Saxe, Central Public Health Laboratory, Colindale, London.

A total of 3108 strains isolated from cases of bacteraemia from 1977-1982 were surveyed for loss of penicillin resistance in the period between primary isolation and the second testing for antibiotic susceptibility (table I, part 1). From this material, 46 strains were chosen for further investigation of the stability of the penicillinase property (table I, part 2).

Five penicillin-resistant strains, all isolated before 1977 , with heavy-metal resistance to arsenate only, were examined quantitatively for penicillinase production. Two of them belonged to the $83 \mathrm{~A}$ complex and one each to groups I, II and III.

The relationship between strains of phage type 95 and other strains was studied in 2586 strains isolated from cases of bacteraemia during 1977-1981. The 2586 strains included penicillin-resistant and penicillin-susceptible strains, but strains lysed by phage 95 only (at routine test dilution; RTD) were omitted. The 2586 strains were surveyed for sensitivity to typing phage 95 ; a similar survey was made of all 311 strains of the $52,52 \mathrm{~A}, 80,81$ complex isolated from 1970-1976.

Phage typing was performed according to the methods of Blair and Williams (1961) and Rosendal et al. (1976). Phage 95 (Parker, 1984) was included in the basic set of routine typing phages in 1977. The non-typable strains among the pre-1977 bacteraemia isolates which had been kept freeze-dried, were re-tested with phage 95 at RTD. A strain was regarded as belonging to phage type 95 if it was lysed at RTD by this phage only.

Lysogenisation and isolation of phages from three type-95 strains were as described by Rosendal and Bülow (1965).

Susceptibility to cadmium acetate $(\mathrm{Cd})$, sodium arsenate ( $\mathrm{As}$ ) and mercuric chloride $(\mathrm{Hg}$ ) was determined as described by Rosdahl and Rosendal (1980). The resistance patterns were denoted as: susceptible (susceptible to all three metals), As (resistant to As only) and Cd, As (resistant to $\mathrm{Cd}$ and $\mathrm{As}$, susceptible to $\mathrm{Hg}$ ).

Antibiotic susceptibility testing was performed as described by Rosendal et al. (1981). Before further investigations with these strains on stability and penicillinase production, their antibiotic susceptibility was re-tested by the PDM (AB Biodisk) method described by Ericsson et al. (1954) against penicillin, streptomycin, tetracycline, erythromycin, methicillin, gentamicin and fusidic acid.

Criteria for loss of penicillin resistance. The bacteraemia strains were preserved in agar stabs for 11-22 months before the second testing for antibiotic susceptibility. Broth cultures from these stabs were subcultured on blood-agar plates from which 3-5 colonies were inoculated into broth. After incubation, these broth cultures were used for antibiotic susceptibility testing. A strain was considered penicillin susceptible if no penicillinase-producing colonies were observed in the penicillin inhibition zone. If the strain had been penicillin resistant at the time of isolation, but was found to be susceptible at the second testing, it was recorded as having lost penicillin resistance (table I, part 1).

Penicillinase-producing colonies were detected on starch plates according to Dyke et al. (1966), except that methicillin was omitted.

Quantitative penicillinase determination was as described by Rosdahl and Rosendal (1983).

Storage medium was Bacto Beef Extract (Difco) $50 \mathrm{~g}, \mathrm{NaCl} 50 \mathrm{~g}$, peptone $100 \mathrm{~g}$ and Japanese agar $50 \mathrm{~g}$ in demineralised water $10 \mathrm{~L}$. The $p \mathrm{H}$ was adjusted to 7.2 and the medium poured into tubes ( $10 \mathrm{~mm}$ diameter) to a height of 3-4 cm. The tubes were closed with waxed cork stoppers. Another similar storage medium was prepared with agar $100 \mathrm{~g}$ instead of $50 \mathrm{~g}$, and with LabLemco powder $40 \mathrm{~g}$ instead of Bacto Beef Extract $50 \mathrm{~g}$.

Loss of penicillinase production during storage was investigated by stab-inoculating a penicillinase-positive colony of the strain into storage medium which was then kept in the dark at room temperature. At the time of investigation a broth culture was prepared from the stab and plated on to 10 starch plates with $c .100 \mathrm{cfu} /$ plate. After flooding with penicillin-iodine solution, the number of penicillinase-negative and penicillinase-positive colonies was counted. One colony of each strain was phage-typed to exclude contamination. 


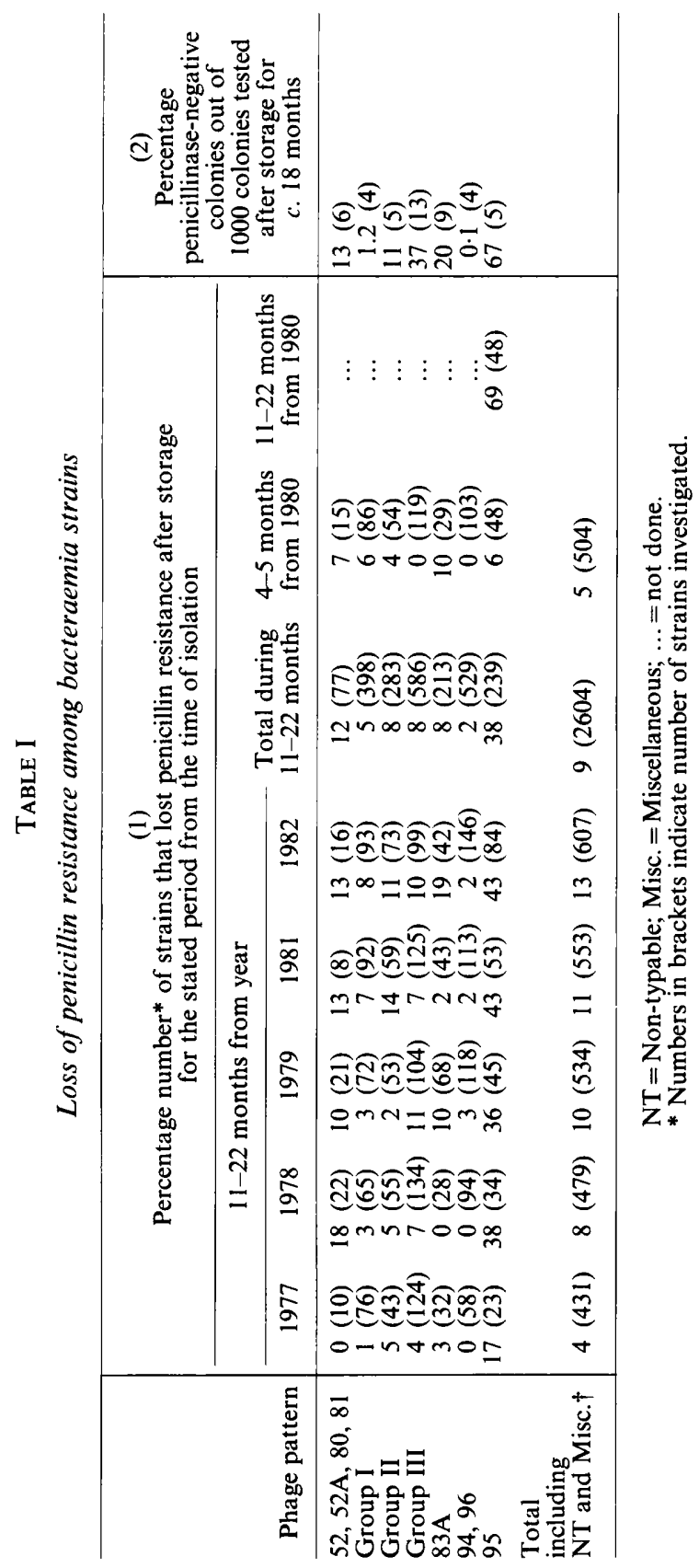


Growth rate. A broth culture with a density of $c .10^{5} \mathrm{cfu} / \mathrm{ml}$ was prepared and allowed to grow at $37^{\circ} \mathrm{C}$. Samples were then taken for viable counts every hour for $10 \mathrm{~h}$ and after $24 \mathrm{~h}$.

Isolation of plasmid DNA was done on $\mathrm{CsCl}$ gradients (Novick et al., 1979).

\section{RESULTS}

\section{Instability of the penicillinase gene in $S$. aureus of phage type 95}

\section{Loss of penicillin resistance among bacteraemia strains isolated in 1977-1982}

The percentage numbers of strains within the various phage groups or complexes that lost penicillin resistance are shown in table I, part 1 . The period of storage varied (see Methods) from 11 to 22 months, depending upon the time of primary isolation of the strain. The loss correlated with the phage type of the strains: highest loss rates (17$43 \%$ ) were recorded with type-95 strains, lowest $(0-3 \%)$ with the $94 / 96$ strains, and intermediate rates (never greater than $19 \%$ ) with the other strains. This pattern was constant, but the total percentage loss varied from year to year (probably due to varying conditions of storage). Furthermore, the period of storage influenced the loss of penicillin resistance. In 1980, the second testing of antibiotic susceptibility was done after only 4-15 months, and a very small proportion of strains had lost their penicillin resistance, but a considerable increase from $6 \%$ to $69 \%$ was noted among the 48 type- 95 strains re-examined 7 months later. No loss of penicillin resistance was detected in strains stored for $<10$ months.

The above results were confirmed by further investigations of 46 strains of different phage types. Broth cultures from 18-month-old stabs were spread on plates, and the numbers of penicillinase-negative colonies were recorded (table I, part 2); loss rates of $67 \%$ for the type-95 strains, $37 \%$ for the group-III strains and only $0 \cdot 1 \%$ for the 94,96 strains were noted. In two of the five type-95 strains, all the colonies were penicillinasenegative, but this was never the case with strains of group III.

\section{Loss of penicillinase-producing cells during storage}

A collection of 22 strains of phage type 95 were stabbed into two different storage media and, in addition, kept frozen at $-80^{\circ} \mathrm{C}$. All but two of these showed a decrease in penicillinase-producing colonies cultured from the storage stabs (table II). No significant difference between the two media was found, and the results in table II are mean values from the two investigations. With five strains, all the colonies grown after the stab had been stored for 18 months were penicillinase-negative. The other strains varied from month to month. Penicillinase-negative colonies were never produced by strains stored at $-80^{\circ} \mathrm{C}$ for 18 months or by the two type- 94,96 strains kept in stabs for the same period.

\section{Resistance to cadmium, arsenate and mercury}

Of 380 Danish type-95 strains investigated, 379 had characteristic resistance patterns: 354 were susceptible to all three metal ions, 25 were resistant to As only and one was resistant to $\mathrm{Cd}$ and As. These patterns were found in $14 \%, 0.4 \%$ and $39 \%$ respectively of 1341 penicillin-resistant strains of other phage types (Rosdahl and Rosendal, 1980). 
TABLE II

Percentage number of penicillinase-negative colonies cultured from 22 type-95 strains during storage in stabs*

\begin{tabular}{|c|c|c|c|c|}
\hline \multirow{2}{*}{$\begin{array}{l}\text { Percentage number } \\
\text { of penicillinase- } \\
\text { negative colonies }\end{array}$} & \multicolumn{4}{|c|}{$\begin{array}{l}\text { Number of strains yielding penicillinase- } \\
\text { negative colonies after storage for (months) }\end{array}$} \\
\hline & 2 & 6 & 12 & 18 \\
\hline $\begin{array}{c}0 \\
<1 \\
1-4.9 \\
5.0-9.9 \\
10.0-24.9 \\
25 \cdot 0-49.9 \\
\geqslant 50\end{array}$ & $\begin{array}{l}2 \\
7 \\
7 \\
5 \\
1 \\
0 \\
0\end{array}$ & $\begin{array}{l}2 \\
5 \\
8 \\
0 \\
3 \\
3 \\
1\end{array}$ & $\begin{array}{l}2 \\
3 \\
9 \\
3 \\
1 \\
2 \\
2\end{array}$ & $\begin{array}{l}2 \\
3 \\
7 \\
2 \\
2 \\
1 \\
5\end{array}$ \\
\hline
\end{tabular}

* Percentage calculated after storage in agar stabs at intervals up to 18 months.

\section{Correlation of metal resistance with quantitative penicillinase production}

Quantitative penicillinase production was investigated in 48 type-95 strains; 22 of these, including seven English strains, were susceptible to all three metal ions; 25 were resistant to As and one was resistant to $\mathrm{Cd}$, As.

The strains resistant to As produced much more penicillinase than the susceptible strains (figure); the mean values were 131, 340 and 258 units/mg of bacteria for the susceptible group, the As-resistant and the Cd, As-resistant strains respectively.

Penicillinase production by the five As-resistant strains belonging to the other

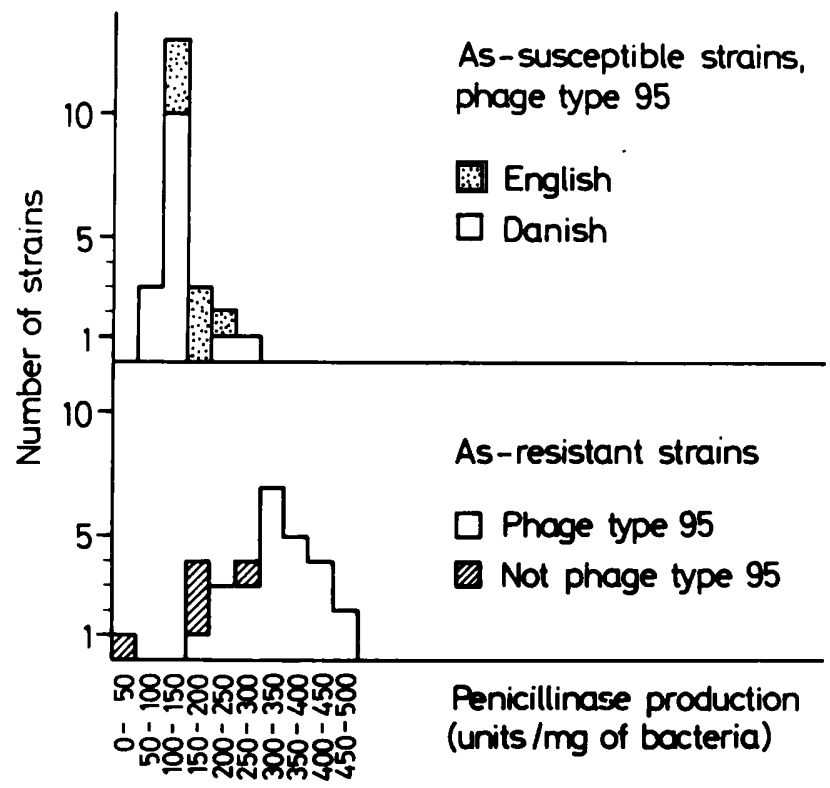

FIG.-Penicillinase production by 47 type-95 strains (22 As-susceptible, 25 As-resistant) and by five Asresistant strains belonging to other phage types. 
phage types was not uniform. Strains of the 83A complex produced much penicillinase, and strains of group II produced only small amounts (Rosdahl and Rosendal, 1983).

There were no significant variations among the type-95 strains as regards the percentage of enzyme excreted in the surroundings or the ratio between the amount of enzyme produced after methicillin induction compared to the basal production without induction.

\section{Genetic properties of strains of phage type 95}

\section{Genetic location of the penicillinase gene in metal-susceptible strains}

Eight metal-susceptible type-95 strains resistant to penicillin only, and their corresponding penicillinase-negative variants, were analysed for the presence of plasmid DNA on $\mathrm{CsCl}$ gradients. All eight contained a plasmid-DNA band that disappeared in studies with seven of the strains when the penicillinase property was lost; one strain retained its plasmid band in the penicillinase-negative variant. The properties of this plasmid were not determined. The two strains of phage type 95 that never lost their penicillinase production had no plasmid DNA. These investigations correspond well with our finding that the penicillin-susceptible variants produced no penicillinase.

No difference between the growth rates of the penicillin-resistant strains and their susceptible variants was observed.

Genetic location of the penicillinase and the As-resistance gene in As-resistant strains of phage type 95

In studies of seven As-resistant type-95 strains, penicillinase production and As resistance were always lost together; a total of 2000 colonies was investigated for each strain. On further analysis of 10000 colonies from two strains, only one As-susceptible colony was found and it produced penicillinase in the same large amounts as the original As-resistant strain.

To determine whether the As-susceptible strains contained a small number of Asresistant variants, the centrifuged deposits from 5-ml volumes of overnight broth cultures of seven As-susceptible strains were spread on plates containing sodium arsenate $400 \mathrm{mg} / \mathrm{L}$. Only one As-resistant colony was isolated; its penicillinase production was 486 units $/ \mathrm{mg}$ of bacteria compared with 110 units/mg of the original As-susceptible strain. The percentage amount of enzyme excreted into the surroundings and the ratio between the amount of enzyme produced after methicillin induction compared to the basal amount without induction were identical in comparative studies with the original and the As-resistant strain.

\section{Probable relationship between strains of phage type 95 and other strains}

\section{Percentage of strains of other phage groups or complexes co-reacting with phage 95}

The 2586 bacteraemia strains isolated during 1977-1981 and typed at RTD were surveyed for sensitivity to typing phage 95 to determine the number of strains 
TABLE III

Percentage number of isolates from the years 1977-1981 within the various groups or complexes that were also lysed by phage 95

\begin{tabular}{lcccccccc}
\hline $\begin{array}{l}\text { Groups or } \\
\text { complexes:C }\end{array}$ & $\begin{array}{c}52,52 \mathrm{~A}, 80,81 \\
\text { complex }\end{array}$ & Group I & Group II & Group III & $\begin{array}{c}83 \mathrm{~A} \\
\text { complex }\end{array}$ & $\begin{array}{c}94,96 \\
\text { complex }\end{array}$ & NI \\
\hline $\begin{array}{l}\text { Percentage* } \\
\begin{array}{l}\text { number lysed } \\
\text { by phage 95: }\end{array}\end{array}$ & $10.3(135)$ & $2.3(501)$ & $0.2(350)$ & $0.7(710)$ & $4.2(234)$ & $0(437)$ & $15.9(219)$
\end{tabular}

"NI" (non-identified strains) includes all strains that reacted with phages of two or more lytic groups (excluding phage 95 ).

* The numbers of strains in the group or complexes are given in brackets.

belonging to the various phage groups or complexes that were susceptible to this phage (table III). The highest percentages were found among strains lysed by phages belonging to more than one lytic group (NI) and among strains of the 52, 52A, 80, 81 complex. Only one group-II strain and none of the 94,96 complex were lysed by phage 95. Of 311 strains of the 52, 52A, 80, 81 complex isolated in 1970-1976, 46(14.7\%) were lysed by phage 95 .

\section{Lysogenisation with phages isolated from three type-95 strains}

When three strains of the 52, 52A, 80, 81 complex and three group-III strains, all of them also susceptible to phage 95 , were lysogenised with phages from three type-95 strains, all previous reactions with other typing phages were blocked.

\section{DISCUSSION}

Asheshov and Winkler (1966) were of the opinion that the 80, 81 strains belonged to one clone because they all harboured two uncommon prophages. The combination of rare properties found in our Danish type-95 strains may allow the same conclusion.

In the majority of type-95 strains, the penicillinase gene is plasmid-borne and is much more unstable than in all other phage types. The amount of penicillinase produced is correlated with two unusual metal-susceptibility patterns. Most type-95 strains produce moderate amounts of penicillinase and are susceptible to all three metals $(\mathrm{Cd}, \mathrm{As}, \mathrm{Hg})$, whereas most other phage types with this metal-susceptibility pattern have stable penicillinase genes. A minority of the type-95 strains are resistant to As (not $\mathrm{Cd}$ or $\mathrm{Hg}$ ) and are uniformly potent producers of penicillinase. With these strains, the simultaneous loss of penicillinase and As resistance suggests a close connection between the two genes although preliminary investigations on gelelectrophoresis might indicate two separate plasmids. Further investigations on the interaction between the penicillinase and the As gene are needed.

It is highly improbable that strains with all these rare properties should evolve $d e$ novo in all strains of type $\mathbf{9 5}$ or in several different ancestors. The facts suggest the spread in Denmark of at most two clones, one major, susceptible to As, and one minor, resistant to As only. It cannot be ruled out that As resistance together with potent penicillinase production have been transferred to As-susceptible strains. Further 
investigations of this possibility including attempts to transfer As resistance to susceptible strains might clarify the problem.

According to the data that we present (table III), the most likely ancestors of the type-95 strains are strains lysed by the phages 52, 52A, 80, 81 either alone or in combination with phages belonging to other lytic groups (NI), but other possibilities cannot be excluded. This evolution implies lysogenisation with phage(s) blocking the sensitivity to all typing phages other than 95 ; the instability of the penicillinase plasmid may reflect an incompatibility between the plasmid and the prophages. More than $90 \%$ of the strains belonging to the 52, 52A, 80, 81 complex are, however, resistant to $\mathrm{Cd}$, As or $\mathrm{Cd}, \mathrm{As}, \mathrm{Hg}$, and the majority of these strains are resistant to penicillin and streptomycin. Among the strains resistant to penicillin only $4 \%$ are susceptible to $\mathrm{Cd}$, $\mathrm{As}, \mathrm{Hg}$, and strains of phage type $95 \mathrm{might}$ have evolved from these few strains. Another possibility is that the penicillinase gene of the 52,52A, 80,81 complex has been modified from $\mathrm{Cd}$, As and $\mathrm{Cd}, \mathrm{As}, \mathrm{Hg}$ to either susceptible or As, or that the original plasmid has been totally lost and substituted by a new and more unstable penicillinase plasmid.

It has been suggested previously that the ability to produce much penicillinase might be a characteristic of the "hospital staphylococcus" (Richmond et al., 1964; Rosdahl and Rosendal, 1983). If so, it may be expected that the As-resistant type-95 strains will outnumber the As-sensitive ones in the future. Our present data do not allow a statistical evaluation, but in the first 3 years of the period $1977-1982,4.9 \%$ of the type-95 strains were As-resistant as against $8.1 \%$ in the last 3 years.

The future spread of the type-95 strains will be monitored with special attention to the susceptibility of these strains to heavy metals and mortality rates among bacteraemic patients. In a previous investigation, it was shown that mortality could be correlated with the amount of penicillinase produced by the infecting strain (Rosendal et al., 1983). Accordingly, it might be expected that mortality is correlated with resistance to As in infections caused by type- 95 strains. The present findings suggest such a correlation.

\section{REFERENCES}

Asheshov E H, Winkler K C 1966 Staphylococcus aureus strains in the "52, 52A, 80, 81 complex". Nature 209:638-639.

Blair J E, Williams R E O 1961 Phage typing of staphylococci. Bulletin of the World Health Organization 24:771-784.

Dyke K G H, Jevons M P, Parker M T 1966 Penicillinase production and intrinsic resistance to penicillins in Staphylococcus aureus. Lancet 1:835-838.

Ericsson H, Hogman C, Wickman K 1954 A paper disk method for determination of bacterial sensitivity to chemotherapeutic and antibiotic agents. Scandinavian Journal of Clinical Laboratory Investigation, suppl 11: 21-36.

Jessen O, Rosendal K, Bülow P, Faber V, Eriksen, K R 1969 Changing staphylococci and staphylococcal infections. A ten year study of bacteria and cases of bacteraemia. New England Journal of Medicine 281:627-635.

Jevons M P, John M, Parker M T 1966 Cultural characters of a newly recognized group of hospital staphylococci. Journal of Clinical Pathology 19:305-312.

Novick R P, Murphy E, Gryczan T J, Baron E, Edelman I 1979 Penicillinase plasmids of Staphylococcus aureus: restriction-deletion maps. Plasmid 2:109-129.

Parker M T 1984 The significance of phage-typing patterns in Staphylococcus aureus. In: Easmon C S F, Adlam C (eds) Staphylococci and staphylococcal infections, vol 1. Academic Press, London. 
Richmond M H, Parker M T, Jevons M P, John M 1964 High penicillinase production correlated with multiple antibiotic resistance in Staphylococcus aureus. Lancet 1:293-296.

Rosdahl V T, Rosendal K 1980 Resistance to cadmium, arsenate, and mercury among Danish strains of Staphylococcus aureus isolated from cases of bacteriaemia, 1957-74. Journal of Medical Microbiology 13:383-391.

Rosdahl V T, Rosendal K 1983 Correlation of penicillinase production with phage type and susceptibility to antibiotics and heavy metals in Staphylococcus aureus. Journal of Medical Microbiology 16:391-399.

Rosendal K, Bülow P 1965 Temperate phages influencing lipase production by Staphylococcus aureus. Journal of General Microbiology 41:349-356.

Rosendal K, Bülow P, Bentzon M W, Eriksen K R 1976 Staphylococcus aureus strains isolated in Danish hospitals from January 1st, 1966 to December 31st, 1974. Acta Pathologica et Microbiologica Scandinavica, sect. B 84:359-368.

Rosendal K, Bang J, Rosdahl V T 1981 Gentamicin-resistant Staphylococcus aureus strains isolated in Denmark in 1979. Acta Pathologica et Microbiologica Scandinavica, sect. B 89:185-191.

Rosendal K, Jessen O, Faber V, Bentzon M W 1983 Frequency, phage types and antibiotic resistance of Staphylococcus aureus isolated from blood cultures in Denmark 1975-1981. Scandinavian Journal of Infectious Diseases suppl. 41:19-26. 